\title{
I mplant Placement in a Compromised Region - Ridge Split Technique
}

Anusha Nallapuํ, J agadish Reddy G², Raja Babu P³, J uliet J osephin J ${ }^{4}$

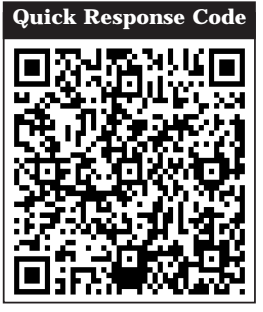

doi: $10.5866 / 2016.8 .10198$

${ }^{1}$ Post Graduate student

${ }^{2 \& 4}$ Reader

${ }^{3}$ Professor \& HOD

Department of Periodontics,

Kamineni Institute of Dental Sciences,

Narketpally, Nalgonda, Telangana.

\section{Article Info:}

Received: J uly 10, 2016

Review Completed: August 9, 2016

Accepted: September 11, 2016

Available Online: December, 2016 (www.nacd.in)

(c) NAD, 2016 - All rights reserved

\section{Email for correspondence:}

drnallapuanusha@gmail.com

\section{Introduction:}

At present, patients are more interested in dental treatments with better esthetic results and less treat-ment time. Rehabilitation of occlusion with dental im-plants is considered one of the most efficient treatment methods for edentulism. ${ }^{1}$ While implant dentistry has become a desirable option for replacement of missing teeth, the available bone foundation determines the possibility of implantation. ${ }^{2}$

Lack of sufficient bone to place an implant at the functionally and aesthetically most appropriate position is a common problem. ${ }^{3,4}$ To facilitate osseointegration and avoid bone resorption, narrow, edentul ous al veol ar bony ridges less than 5-mm wide require bone augmentation prior to implant

\section{ABSTRACT:}

Introduction: Narrow alveolar ridges especially in the posterior mandibular remains a serious challenge for successful placement of endosseous implants.

Case presentation: The present case report addresses surgical procedures for widening the atrophic ridge of edentulous ridge as thin as $3 \mathrm{~mm}$ and gradual expansion in the posterior mandibular ridge, then simultaneous placement of dental implant. A significant increase was achieved in the bone dimension, which enabled the placement of endosseous dental implants successfully.

Discussion: This segmental ridge slit procedure with gradual bone expansion provides a quicker method wherein an atrophic ridge can be predictably expanded and eliminating the need for a second surgical site. This techniqueal so shows that immediate implantation in split ridge of mandible can be performed.

Key words: Endosseous implants, alveolar bone loss, oseteotomy. 
implant sites by bone osteotomies that enable buccal cortex repositioning after greenstick fracture of the buccal bony wall. Since its introduction, many studies have attempted to prove that the alveolar ridge split technique is a good alternative to traditional alveolar augmentation procedures. ${ }^{8-10}$

Treatment of atrophic ridge especially in posterior man-dibular is accompanied with great problem in achiev-ing successful results with endosseous implants. ${ }^{3,4}$

According to Atwood knife-edge crests might be managed by conventional bone grafting, guided bone augmentation procedures by using membranes, and various other techniques. ${ }^{11}$ Ridge augmentation by bone graft requires a second surgery for a later implantation, thus lengthening the treatment time and cost. Ridge splitting technique which causes lateral ridge expansion creates new im-plant bed by longitudinal osteotomy positioning buc-cal cortex laterally. ${ }^{5}$

The present clinical report describes the technique for ridge splitting, gradual expansion in the mandible and simultaneous implant placement within the split ridge.

\section{Case Report:}

A 24-year-old systemically healthy male patient reported to the Department of Periodontology, Kamineni I nstitute of Dental Sciences, N arketpally, Telangana, with a chief complaint of bleeding gums and missing tooth number of 46. Patient's medical history was noncontributory. Extra-and intraoral examinations had normal findings, and his dentition was in a good state of repair. Dental history revealed missing mandibular right teeth number 46 , which had been extracted fiveyears ago. Radiographicand clinical examination revealed inadequate buccolingual dimension of bone at the crest for implant placement, with sufficient height (Figure 1). There was adequate cortical and cancellous bone to allow ridge expansion. It was decided to place immediate implants, using the split control expanding technique. After administrating adequate local an-esthesia, a mid-crestal incision and intracrevicular incisions were made around buccal aspect of adjacent teeth. Full thickness mucoperiosteal flaps were raised on the buccal and lingual aspects of cortical plates but minimal tissue reflection was per-formed in lingual aspect to preserve the periosteum at-tachment surrounding the buccal and lingual bone (Figure 2). This was performed to prevent possible buccal bone plate crack. Keeping the periosteum intact would facilitate re-positioning of the fragments and achieve good healing. Corticotomy was performed with a pizeotome facilitating the os-teotomy of region. The horizontal osteotomy line was cut along the narrow crest using a piezotome burs, 1 to $2 \mathrm{~mm}$ away from the second molar till the first premolar region on the right side of the mandible under saline irrigation. Then the osteotomy line was deepened. Two additional vertical cuts were created on the buccal plate at the mesial and distal end of the horizontal incision. Osteotomes of increasing size and chisels were used for the progressive lateralization of the buccal plate. A sequence of expansion drill of increasing width in the selected site was used to allow more gradual bone expansion. Then the implant site was prepared using final twist drills and implant of $4.2 \mathrm{~mm} \times 10 \mathrm{~mm}$ was placed in molar region. Allograft material was used to fill the space and resorbable membrane is placed and it is stabilized by cover screw (Figure 3). Then tension free mucoperiosteal tis-sue closure was performed over implant using 3-0 non--resorbable suture (Figure 4) Non steroidal analgesics, Amoxicillin 500 $\mathrm{mg}$ and $0.2 \%$ chlorhexidine mouth rinse was the preoperative protocol administered for the patient. Sutures were removed after 10 days. After 3months prosthesis is placed (Figure 5 )

A significant increase was achieved in the bone dimen-sion, which enabled the placement of endosseous dental implant successfully. Then after preparation of the im-plant site, implant of $4.2 \mathrm{~mm}$ $\times 10 \mathrm{~mm}$, was placed in molar region. The present report demonstrated the successful use of expanding the poste-rior mandibular alveolar ridge. It also showed that this technique allows for immediate implant placement.

\section{Discussion:}

Vari-ous surgical widening techniques have been described, including lateral augmentation with or without guided bone regeneration (GBR), ridge expansion osteotomy, ridge splitting technique with or without interpositional grafting and horizontal distraction osteogenesis. ${ }^{12-19}$

The buccal cortex is positioned laterally to create space between buccal and lingual cor-tical plates, which is filled by endosseous implant with or without any graft material.6,20 This technique is 


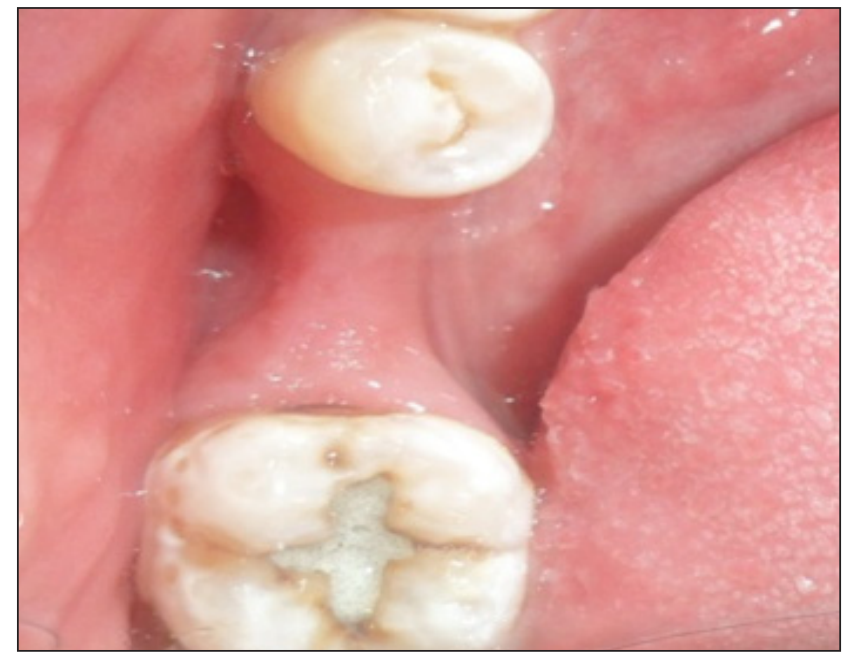

Figure 1: Clinical picture showing inadequate buccolingual dimension of bone at the crest for implant placement

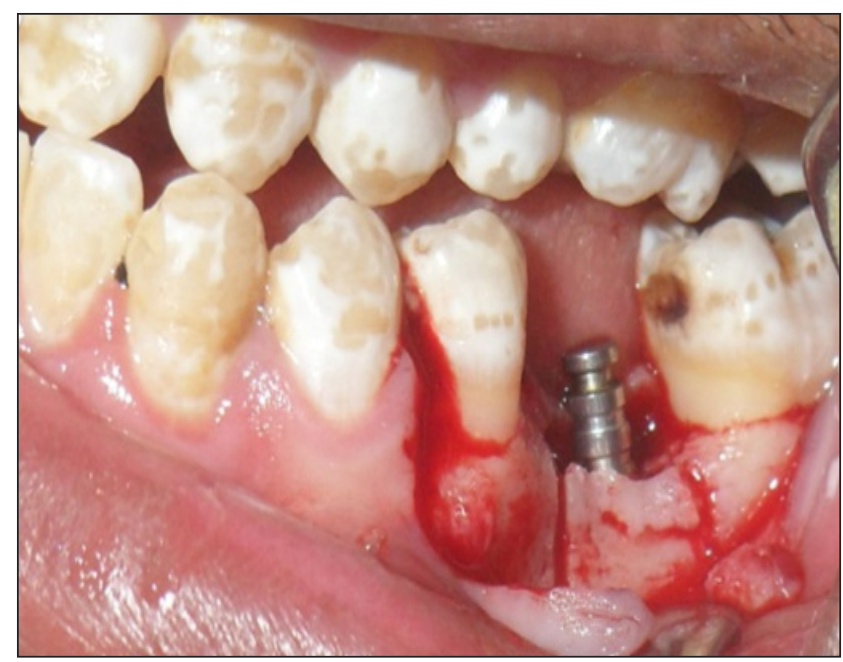

Figure 3: Allograft material was used to fill the space and resorbable membrane is placed and it is stabilized by cover screw

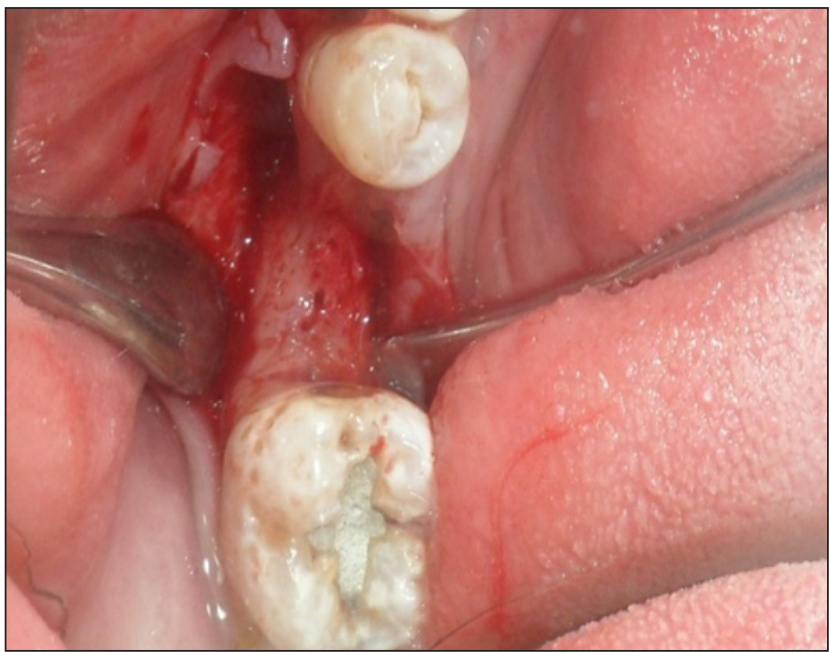

Figure 2: Operative picture showing after flap elevation

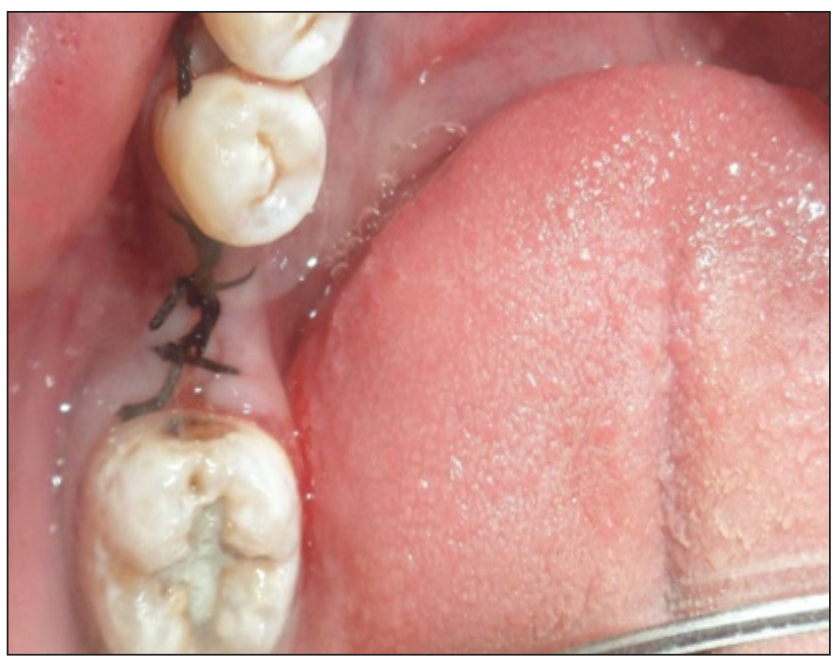

Figure 4: Tension free mucoperiosteal tissue closure was performed over implant using 3-0 non--resorbable suture

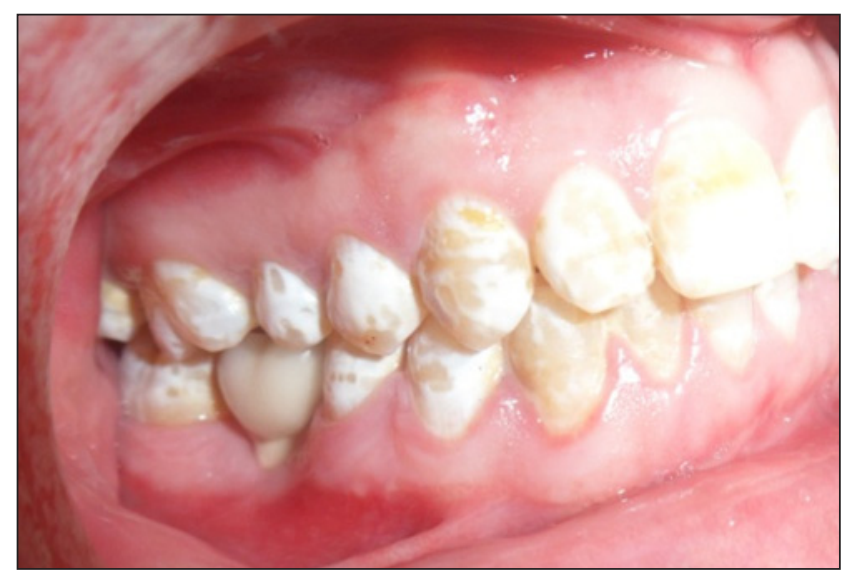

Figure 5: Sutures were removed after 10 days and after 3 months prosthesis is placed. 
performed with immediate implant placement, which decreases the treatment time significantly.

A staged approach to ridge splitting in the mandible can be performed to avoid complications. Another tech-nique for placement of dental implants in narrow bone ridges is repositioning and remodeling of alveolar bone by controlled expansion. This technique uses screw-type configuration osteotomes and thread formers with increasing diameters. ${ }^{21}$

H orizontal atrophy of the alveolar ridge usually complicates adequate implant placement. GBR, bone grafting, alveolar ridge splitting and combinations of these techniques have been suggested as treatment modalities to increase bucco-lingual dimension of the residual ridge. 7 , 9, 21-31 The ridge splitting technique is used for the horizontal augmentation of narrow alveolar ridges and allows simultaneous implant placement. Low morbidity and short treatment time are the major advantages of this technique compared to GBR and bone grafting procedures. ${ }^{5,}$ 32-34

The posterior mandible is the most difficult region for reconstruction and early implantation in cases of severe alveolar resorption in the maxillamandibular complex. Onlay grafting with biodegradable membranes and au-tografts is the most frequently used technique; however, this technique involves a long ossification period, and the tendency of the graft material to resorb can easily decrease bone quality and quantity. ${ }^{35}$ Time lost and donor-side morbidity are the main disadvantages of this reconstructive approach. The split-crest technique should be delineated as a bone expansion procedure, which potentially eliminates the overall disadvantages of Onlay grafting for esthetic and functional demands. ${ }^{36}$ Chiapasco et al . evaluated the efficiency of different sur-gical techniques for ridge reconstruction and success rates of implants placed in the augmented areas. ${ }^{11}$

The surgical success and the implant survival rates were as high as the guided bone regeneration and onlay graft procedure, with the advantage of a shorter treatment time. ${ }^{11}$ Car eful preparation of the bone and maintenance of an attached periosteum are critical to the formation of new bone around the interproximal surfaces of the implants. Wound healing in these cases is similar to the fracture repair of bone. The gap is filled with a blood clot, which is organized and replaced with woven boneand further matures into load-bearing lamellar bone at the implant interface. ${ }^{35}$

Strong evidence for the effectiveness and the predictability of the ridge splitting technique is available in the literature. Clinical trials have reported success rates ranging from 98 to $100 \%$. The survival rates of implants immediately placed in expanded sites ranged from $91 \%$ to $97.3 \%$, while the success rates varied from $86.2 \%$ to $98.8 \%, 8,9,16,37,38$

Complications during thesurgical procedureare very rare - fracture of the buccal bone plate being reported as a major complication of the technique. ${ }^{39}$ Controlled force application and gradual expansion could prevent malfractures. ${ }^{40,41}$ In addition, a thorough preoperative evaluation is very important. The thickness of the cortical plates and the amount of the intervening cancellous bone must be carefully assessed preoperatively by dental CT scans. Last but not least, fabrication of radiographic/ surgical guide can prevent improper implant placement and angulation. If favorable condi-tions are not present, clinician might prefer Onlay aug-mentation. Therefore, appropriate case selection and sur-gical technique is of great importance when considering the application of this technique.

Conclusion: The ridge splitting technique seems to be a minimally invasive option for horizontal augmentation of narrow alveolar ridges. Predictable clinical results can be achieved as long as a proper preoperative evaluation is performed and a precise surgical protocol is followed.

\section{References}

1. Zarb GA, Schmitt A. The longitudinal clinical effectiveness of os-seointegrated dental implants: the Toronto Study. Part II: The prosthetic results. J Prosthet Dent 1990; 64(1):53-61.

2. Neophytos Demetriades, J ong il Park, Constantinos Laskarides. Alternative Bone Expansion Technique for Implant Placement in Atrophic Edentulous Maxilla and Mandible. J Orall mplantolo 2011; 37(4):463-71.

3. Garg AK, Morales MJ , Navarro I, Duarte F. Autogenous man-dibular bone grafts in the treatment of the resorbed maxillary anterior alveolar ridge: rationale and approach. Implant Dent 1998; 7(3):169-76.

4. Buser D, Dula K, Lang NP, Nyman S. Long-term stability of osseo-integrated implants in bone regenerated with the membrane technique. 5-year results of a prospective study with 12 implants. Clin Oral Implants Res 1996; 7(2):17583.

5. Enislidis G, Wittwer G, E wers R. Preliminary report on a staged ridge splitting technique for implant placement in the mandible: a technical note. Int J Oral Maxillofac Implants 2006; 21:445-9. 
6. Basa S, Varol A, Turker N. Alternative bone expansion technique for immediate placement of implants in the edentulous posterior mandibular ridge: a clinical report. Int J Oral Maxillofac Implants 2004; 19:554-8.

7. Tatum $\mathrm{H}$. Maxillary and sinus implant reconstructions. Dent Clin North Am 1986; 30:207-29.

8. Scipioni A, Bruschi GB, Calesini G. The edentulous ridge expansion technique: a five-year study. Int J Periodontics Restorative Dent 1994; 14:451-9.

9. Sethi A, KausT. Maxillary ridgeexpansion with simultaneous implant placement: 5-year results of an ongoing clinical study. Int J Oral Maxillofac Implant 2000; 15:491-9.

10. Summers RB. A new concept in maxillary implant surgery: the osteotome technique. Compend Contin E duc Dent 1994; 15:152-60.

11. Atwood DA. Some clinical factors related to rate of resorption of residual ridges. 1962. J Prosthet Dent 2001; 86(2):119-25

12. Chiapasco M, Abati S, Romeo E, Vogel G. Clinical outcome of au-togenous bone blocks or guided bone regeneration with $\mathrm{e}$ PTFE membranes for the reconstruction of narrow edentulous ridges. Clin Oral Implants Res 1999; 10(4):278-88.

13. De Boever AL, De Boever J A. A one-stage approach for nonsub-merged implants using a xenograft in narrow ridges: report on seven cases. Int J Periodontics Restorative Dent 2003; 23(2):169-75.

14. Bedrossian E, Tawfilis A, Alijanian A. Veneer grafting: a tech-nique for augmentation of the resorbed alveol us prior to im-plant placement. A clinical report. Int J Oral Maxillofac Implants 2000; 15(6):853-8.

15. Summers RB. The osteotome technique: Part 2-The ridge expan-sion osteotomy (REO) procedure. Compendium 1994; 15(4):422- 4.

16. Lustmann J, Lewinstein I. Interpositional bone grafting tech-nique to widen narrow maxillary ridge. Int J Oral Maxill ofac Im-plants 1995; 10(5):568-77.

17. Engelke WG, Diederichs CG, J acobs HG, Deckwer I. Alveolar re-construction with splitting osteotomy and microfixation of im-plants. Int J Oral Maxillofac I mplants 1997; 12(3):310-8.

18. Simion M, Baldoni M, Zaffe D. J awbone enlargement using imme-diate implant placement associated with a split-crest technique and guided tissue regeneration. Int J Periodontics Restorative Dent 1992; 12(6):462-73.

19. Takahashi T, Funaki K, Shintani H, Haruoka T. Use of horizontal alveolar distraction osteogenesis for implant placement in a narrow alveolar ridge: a case report. Int J Oral Maxillofac I mplants 2004; 19(2):291-4.

20. Misch CM. I mplant site development using ridge splitting tech-niques. Oral Maxillofac Surg Clin North Am 2004; 16(1):65-74.

21. Misch CM. Use of the mandibular ramus as a donor site for onlay bone grafting. J Oral Implantol 2000; 26(1):42-9.

22. Buser D, Brägger U, Lang NP, Nyman S. Regeneration and enlargement of jaw bone using guided tissue regeneration. Clin Oral Implants Res 1990; 1:22-32.

23. Nevins M, MellonigJ T, Clem DS 3rd, Reiser GM, BuserDA. I mplants in regenerated bone: Iong-term survival. Int J Periodontics Restorative Dent 1998; 18:34-45.

24. Brunel G, Brocard D, Duffort J F, J acquet E, J ustumus P, Simonet $\mathrm{T}$, Benque $\mathrm{E}$. Bioabsorbable materials for guided bone regeneration prior to implant placement and 7-year follow-up: report of 14 cases. J Periodontol 2001; 72:257-64.
25. Hammerle $\mathrm{CH}, \mathrm{J}$ ung RE. Bone augmentation by means of barrier membranes. Periodontol 2000, 2003; 33:36-53.

26. J ung RE, Ledoux G, Rompen E, Ramel CF, Buser D, Hammerle $\mathrm{CH}$. A feasibility study evaluating an in situ formed synthetic biodegradablemembranefor guided boneregeneration in dogs. Clin Oral Implants Res, 2009; 20:151-61.

27. Lekholm U, Wannfors K, Isaksson S, Adielsson B. Oral implants in combination with bone grafts. A 3-year retrospective multicenter study using the Branemark implant system. Int J Oral Maxillofac Surg, 1999; 28:181-7.

28. Chiapasco M, Romeo E, Vogel G. Tridimensional reconstruction of knife-edge edentulous maxillae by sinus elevation, onlay grafts, and sagittal osteotomy of the anterior maxilla: preliminary surgical and prosthetic results. Int J Oral Maxillofac Implants 1998; 13:394-9.

29. Bahat O, Fontanessi RV. Efficacy of implant placement after bone grafting for three-dimensional reconstruction of the posterior jaw. Int J Periodontics Restorative Dent 2001; 21:220-31.

30. Suh JJ, Shelemay A, Choi SH, Chai J K. Alveolar ridge splitting: a new micro saw technique. Int J Periodontics Restorative Dent 2005; 25:165-71.

31. Blus C, Szmukler-Monder S, Vozza I, Rispoli L, Polastri C. Split-crest and immediate implant placement with ultrasonic bone surgery (piezosurgery): 3-year follow-up of 180 treated implant sites. Quintessence Int 2010; 41:463-9.

32. Han J Y, Shin SI, Herr Y, K won YH, Chung J H. The effects of bone grafting material and a collagen membrane in the ridge splitting technique: an experimental study in dogs. Clin Oral Implants Res 2011; 22:1391-8.

33. Piccinini M. Mandibular bone expansion technique in conjunction with root form implants: a case report. J Oral Maxill ofac Surg, 2009; 67(9):1931-6.

34. Demarosi F, Leghissa GC, Sardella A, Lodi G, Carrassi A. Localised maxillary ridge expansion with simultaneous implant placement: a case series. Br J Oral Maxillofac Surg, 2009; 47:535-40.

35. I gnatius AA, Ohnmacht M, Claes LE, Kreidler J, Palm F. A com-posite polymer/tricalcium phosphate membrane for guided bone regeneration in maxillofacial surgery. J Biomed Mater Res 2001; 58(5):564-9.

36. Massoumeh Khoshhal, Parviz Torkzaban, Fariborz Vafaee, Shilan Razaghi. Mandibular Ridge Splitting and Gradual Bone Expansion Technique for Immediate Placement of Implant in the Posterior Thin Region: A Clinical Report. Avicenna J Dent Res 2013; 5(2): e19463.

37. Bravi F, Bruschi GB, Ferrini F. A 10-year multicenter retrospective clinical study of 1715 implants placed with the edentulous ridge expansion technique. Int J Periodontics Restorative Dent 2007; 27:557-65.

38. Chiapasco M, Ferrini F, Casentini P, Accardi S, Zaniboni $M$. Dental implants placed in expanded narrow edentulous ridges with the Extension Crest device. A 1-3 year multicenter follow-up study. Clin Oral Implants Res 2006; 17(3):265-72.

39. Chiapasco M, Zaniboni M, Boisco M. Augmentation procedures for the rehabilitation of deficient edentulous ridges with oral implants. Clin Oral Implants Res 2006; 17:136-59.

40. Sohn DS, Lee HJ , Heo J U, Moon J W, Park IS, Romanos GE. I mmediate and delayed lateral ridge expansion technique in the atrophic posterior mandibular ridge. J Oral Maxill ofac Surg 2010; 68:2283-90.

41. Siddiqui AA, Sosovicka M. Lateral bone condensing and expansion for placement of endosseous dental implants: a new technique. J Oral Implantol 2006; 32(2):87-94. 